Maneras de habitar los espacios desde la mirada estética

Julio 2021

\section{Paisajes fronterizos. Movilidad humana y límites desde una mirada artístico- antropológica}

\author{
Border landscapes. Human mobility and \\ limits from an artistic-anthropological \\ perspective
}

Sugerencias para citar este artículo:

Piñeiro Aguiar, Elder; Lorenzo Castiñeiras, Juan José. (2021). Paisajes fronterizos. Movilidad humana y límites desde una mirada artísticoantropológica. Tercio Creciente 20, (pp. 111127), https://dx.doi.org/10.17561/rtc.20.6156

PIÑEIRO AGUIAR, ELDER; LORENZO CASTIÑEIRAS, JUAN JOSÉ. Paisajes fronterizos. Movilidad humana y límites desde una mirada artístico-antropológica. Tercio Creciente, julio 2021, pp. 111-127, https:// dx.doi.org/10.17561/rtc.20.6156
Elder Piñeiro Aguiar elederpa1983@gmail.com Universidad da Coruña (España)

\author{
Juan José Lorenzo Castiñeiras \\ j.lorenzo.castineiras@udc.es \\ Universidad da Coruña (España)
}

Recibido: 20/02/2021 Revisado: 22/04/2021 Aceptado: 13/06/2021 Publicado: 31/07/2021

\section{Resumen}

La propuesta presentada parte de un enfoque multidisciplinar fundamentado en una lectura, desde la Antropología y la Sociología, de diversas aportaciones procedentes del campo artístico para reflexionar acerca de la movilidad humana y las fronteras en la actualidad. Consideramos el campo del arte propicio para tomar conciencia de una problemática invisibilizada, más aún en tiempos de pandemia, para trasladarnos de modo proactivo y desde el diálogo propositivo. A partir de las performances de Arantxa Araújo (2017), el activismo fotográfico de José Palazón (2015), las obras escultóricas de Bruno Catalano
Abstract

The proposal presented is based on a multidisciplinary approach based on a reading, from Anthropology and Sociology, of various contributions from the artistic field to reflect on human mobility and borders today. We consider the field of art conducive to becoming aware of an invisible problem, even more so in times of pandemic, to move proactively and from the proactive dialogue. From the performance of Arantxa Araújo (2017), the photographic activism of José Palazón ( 2015), the sculptural works of Bruno Catalano (2014) or the symbolic representations of Roman Ondák (2012), we approach the 


\section{Tercio Creciente}

DOI: https://dx.doi.org/10.17561/rtc.20.6156 Investigación
Maneras de habitar los espacios desde la mirada estética Julio 2021
(2014) o las representaciones simbólicas de Roman Ondak (2012), nos aproximamos a las vidas desplazadas de la migración internacional desde categorías antropológicas tales como los límites, la fronterización, el paisajismo étnico, las jerarquías establecidas en las condiciones del desplazamiento o las asimetrías globales. Desde esta posición, prestaremos atención a las condiciones de permanente precariedad en las que se produce un tránsito que, las más de las veces, se convierte en una permanente búsqueda del destino, auspiciada por las generalizadas políticas de oposición que rigen de modo inflexible la actuación de gobiernos y uniones de éstos en los territorios que desiderativamente constituyen el fin de etapa.

\section{Palabras clave}

Movilidad humana; arte político; minorías; fronterización. displaced lives of international migration from anthropological categories such as limits, borders, ethnic landscaping, hierarchies established in the conditions of displacement or global asymmetries. From this position, we will pay attention to the permanent precarious conditions in which there is a transit that, most of the time, becomes a permanent search for destiny, sponsored by the generalized opposition policies that inflexibly govern the action of governments and unions of these in the territories that desideratively constitute the end of the stage.

\section{Keywords}

Human mobility; political art; minorities; bordering. 


\section{Introducción}

El 20 de enero de 2021 Joe Biden asumió la presidencia de los EEUU como el $46^{\circ}$ Presidente y ese mismo día, entre los documentos que firmó, se encontraba el compromisode detener la construcción del muro que separaría dicho país con su vecino México, proyecto emblemático de su predecesor Donald Trump. Y es que todo lo que rodea a la fronterización se cubre no solamente de factores políticos y económicos, sino también sociales, éticos, simbólicos y rituales. Y en ese sentido, destacando la clara conexión que estos factores tienen con el análisis antropológico, es como queremos encarar el objetivo de este texto, orientado a analizar obras de arte actuales centradas en el campo de la movilidad humana y las fronteras.

En concreto lo que nos interesa es reflexionar, desde la interpretación antropológicaartística, sobre qué sucede en espacios fronterizos en zonas de contacto (Pratt, 2010), colocando el campo migratorio y el proceso de delimitación territorial (también corporal) como eje vertebrador de nuestro análisis. En este sentido rescatamos la importancia de ver-participar en el arte activista desde los años 60, lo cual será clave para comprender nuestra contemporaneidad en la que domina una nueva mirada al cuerpo desde el punto de vista político-económico del neoliberalismo. Un cuerpo y unas subjetividades que, por ejemplo, los artistas accionistas, vienen trabajando desde los años 70 del siglo pasado, encapsulándolo, asfixiándolo, aplicándole violencia y asco, como por ejemplo en la obra de Rudolf Schawarzagler (1966) Acción 6 donde el artista se momifica dejando apenas unos estrechos orificios para poder respirar por la boca, mientras se acerca una bombilla a su cara que nos hace recordar un interrogatorio de las películas policiacas hollywoodenses.

¿Cuerpo encapsulado e interrogado como el de algunos migrantes internacionales detenidos, acusados y deportados? Lo veremos. Y es que se ataca al cuerpo para mostrar que ese cuerpo no pertenece, sino que se trata de cuerpos sociales y que por tanto debería ser sumiso. O en otra lectura, estos artistas que piensan la sociedad postfordista lo que nos están diciendo es que la propia representación ha entrado en crisis. Y lo ha hecho en el campo del arte, pero por supuesto también en el campo de la política. Recordemos el "No nos representan" coreado en las plazas durante el Corralito argentino de principios de Siglo XXI, también entonado en el movimiento Occuppy Wall Street o por parte de los indignados españoles del 15-M. Una crisis de la representación que, de algún modo, sirve para pensar otras formas de hacer democracia y, en nuestro caso, el análisis de las obras artísticas expuestas más abajo tiene que ver precisamente con esto, con ese gran significado vacío que es la democracia en palabras de Zizek.

Pero los cuerpos, decíamos, no solamente deberían ser sumisos, sino que, además, con Foucault, lo son. Son dóciles, disciplinados, normalizados, vigilados y castigados como el del Damiens de "Las palabras y las cosas" (Foucault, 1982) o el de los internados en psiquiátricos de su "Historia de la locura" (Foucault, 1967), entre otros. Pero esto no solo les sucede a las obras de arte de las nuevas propuestas y ni tan siquiera es terreno exclusivo de las sociedades del encarcelamiento foucaultianas, quien retoma el análisis de Goffman (2001) acerca de las “instituciones totales”, por 
ejemplo, en Internados. Le sucede, entre otros, a los millones de migrantes transnacionales que dejan sus lugares de origen para tratar de escapar de los mismos por múltiples motivos y de llegar a nuevos proyectos vitales en las sociedades a las que viajan. Estamos de acuerdo con Levinas (2000), para quien las metáforas de la otredad son el huérfano, la viuda y el extranjero.

Observemos que en las migraciones transnacionales son muchas las víctimas que quedan atrás. Pero nos centramos en el caso del extranjero, un tanto en abstracto, por cuanto entendemos que las relaciones de identidad/alteridad son claves para entender el proceso de racionalidad occidental, desde Heródoto analizando pueblos bárbaros hasta la actualidad. Recordemos el existencialismo extremo de dicho extranjero arrojado a la vida en la obra de Camus, pero también en el extranjero analizado desde la fenomenología de Schutz (1964), para quien más que de una persona se trata de una forma de relación social, una relación, una forma social

Partimos desde la óptica de Jesús Rodríguez (2001) y su obra Inmigrantes, desde la cual reflexiona acerca de la migración africana hacia España, que nos sirve para conectar por ejemplo con Saskia Sassen (2015), para quien el problema de las expulsiones y de las migraciones no es una consecuencia del capitalismo sino un hecho primordial para su desarrollo, un aspecto consustancial al mismo. Y para fortalecer esa conexión tomamos en consideración el concepto de diacrítico elaborado por Frederic Barth (1976), uno de los máximos exponentes del análisis de la identidad desde el punto de vista constructivista. Para este autor una cultura no es una esencia ni una causa, sino una consecuencia derivada, entre otros factores, de cómo interpreta, delinea, produce y reproduce sus límites culturales. Si con Barth el límite es una construcción, desde el punto de vista del arte crítico que aquí presentamos dicho límite es además una ficción estética que debe ser deconstruida, tal como leemos en las obras que analizamos. En concreto hemos seleccionado las obras de Catalano (2014) Palazón (2015) y Araújo (2017), que ocupan los siguientes epígrafes respectivamente. La selección tiene que ver en primer lugar por provenir de 3 campos artísticos diferentes (fotografía, performance, escultura) que creemos pueden aportar mayor diversidad al tema central de las fronteras y de la migración, campo diverso por sí mismo; en segundo lugar, se trata de obras actuales generadas en torno a la crisis económica y financiera global y en donde se pueden insertar categorías migratorias de profundo calado como pueden ser las de los refugiados en Europa, las migraciones Sur-Norte en general y la situación de precariedad y vulnerabilidad de lo que Mezzadra (2005) expone como "devenir migrante", concepto también central de nuestro análisis y que se concreta en las propuestas artísticas seleccionadas. El mismo autor defiende un "derecho de fuga" en la misma obra, lo cual pondremos en consideración en las conclusiones de este texto, retomando la interpretación en torno a los artistas seleccionados, pero también bajo la perspectiva de una antropología política de la migración y de una filosofía y semiótica de la representación. 


\section{Tercio Creciente}

DOI: https://dx.doi.org/10.17561/rtc.20.6156

Investigación
Maneras de habitar los espacios desde la mirada estética

Julio 2021

\section{El campo de golf de Melilla. Detrás Inmigrantes sobre la valla. José Palazón}

Comenzando por Walter Benjamin (1989, p. 58) para el análisis de esta obra "la fotografía es una pieza probatoria" que tiene una significación política y que además inquieta al observador. Dirá Benjamin que una contemplación carente de compromiso ya no es adecuada para las fotografías. Y esa es la intención principal de Palazón, quien expone la desigualdad y el miedo al diferente. Entramos por tanto en unas coordenadas que nos hablan del auge de la securitización internacional para poder comprender lo que sucede en el campo migratorio, por cuanto se trata de un negocio en auge y que para el contexto del Sur europeo desde el que escribimos se metaforiza con el concepto de la construcción de una "Europa fortaleza" (VVAA, 2008):

El Mediterráneo se ha convertido en una fosa real de separación. En Europa se presenta este abismo social como un hecho natural, que se corresponde con la geografía de los diferentes continentes. A un lado se levanta una Europa cuyas viejas ansias de poder y rapacidad colonial se hacen cada día más evidentes. Al otro lado, se dibujan vagamente las "clases peligrosas", que se caracterizan por la pobreza, la migración y por su carácter imprevisible" (Dietrich, 2008: 14).

Una peligrosidad que, a decir de Sassen (2015), tiene que ver a nivel global con las expulsiones, y a nivel interno de los Estados con el aumento del punitivismo. Los Centros de Internamiento para Extranjeros serían el intermediario que une ambas realidades: contexto carcelario cuya funcionalidad es prevenir la migración ilegal, con claros fines persuasivos en donde los derechos humanos son incumplidos (Ferrocarril Clandestino et al, 2010). Pero antes de eso (o teniéndolo como permanente entre los miedos y las potencialidades vitales a que se expone la migración), observemos qué relata Palazón.

Se trata de una fotografía tomada en 2015 en el campo de golf de Melilla, ciudad autónoma del Norte de África, fronteriza con Marruecos y a la vez delimitando con el estrecho de Gibraltar, entrada de mar que separa/une España-Europa de África. 


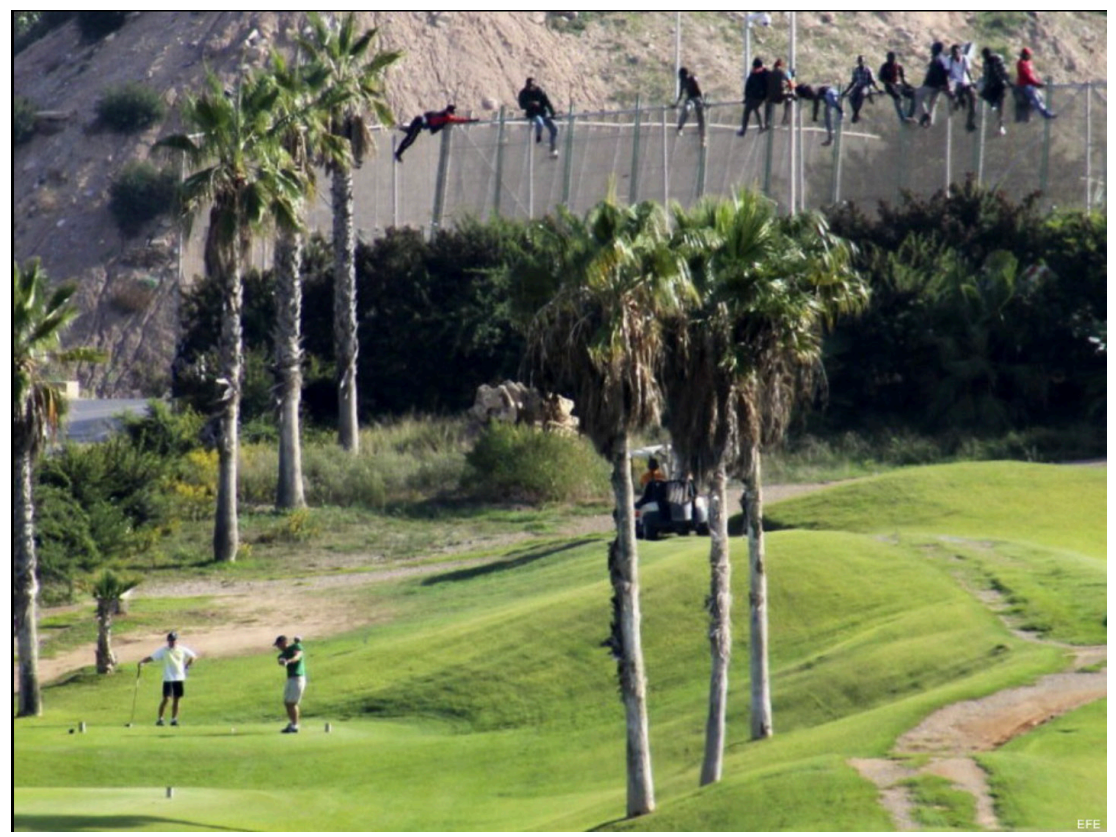

Figura 1.- Migrantes en la valla. José Palazón (2015)

Extraída de https://www.geaphotowords.com/blog/detras-de-una-foto-jose-palazon/ 15/02/2021

Si tomamos como punto de referencia que la toma se realiza teniendo como escenario un campo de golf, podemos estar de acuerdo con Foster (2001) a que asistimos una vez más a una capitalización de la cultura y una privatización de la sociedad bajo el neoliberalismo. A un lado de la valla, nos encontramos por tanto ante un recinto deportivo y club cerrado, cercado, amurallado, amplio, bien cuidado, apto para el ocio de una élite. No solo es cerrado arquitectónicamente, sino que la posibilidad de acceder a él, digamos de manera "normal", pasa por una serie de requisitos, en primer lugar pagando una membresía onerosa. Por otro lado, la imagen de la negritud, categoría fundamental para analizar la migración dada la existencia de categorías raciales desde los inicios de un capitalismo que se globalizó, entre otras cosas, gracias a un comercio internacional triangular que secuestraba africanos para llevarlos a plantaciones caribeñas y americanas con el fin de obtener materias primas. Palazón, por tanto, nos muestra una crítica a las distancias críticas (Foster, 2001, p. 207).

Ese "otro" encaramado a la valla no debe ser solamente una víctima ni tampoco un culpable. Lo que se trata de mostrar, desde el punto de vista del público que observa la escena, es una llamada a la solidaridad, para la cual es necesaria primero la visibilización. Y esta visibilización nos lleva a la obra Walls de López Cuenca (2006) quien desarrolló una videoinstalación en donde en la parte superior aparecen imágenes del salto a la Valla, y en la parte inferior actualizaciones de los resultados de la bolsa del día en que se está filmando. Tenemos pues, con Palazón, no solo un hilo 
continuador de la distancia expuesta por Cuenca entre la valla y el parqué de la bolsa, sino que precisamente en la foto que centra nuestro análisis esto está fijado en un momento concreto: un instante, cualquier instante, un grupo, cualquier grupo...todos los grupos, en cualquier momento, están dispuestos a jugares la vida por condiciones mejores. Mientras, otros (cerca, pero distantes), permanecen en sus espacios y tiempos de recreación, ajenos a la tragedia.

Y es que, al fin y al cabo, ¿cuáles son los derechos del otro en tiempos de desregulación, flexibilidad y precariedad? O con Arendt (2020), ¿cuál es el derecho a tener derechos? o incluso ¿en qué se basa el derecho a reclamar derechos? Tenemos a Rancière (2005, p. 29) para responder a esta pregunta, para quien "en la comunidad política, el excluido es un actor conflictivo". Y así lo muestra el experto en migraciones Javier de Lucas (2016) quien en su obra "Mediterráneo, el naufragio de Europa" utiliza como contraportada la imagen de Palazón para hacer un llamado a la solidaridad, una proclama a la garantía de derechos y un llamamiento hacia un mayor pacto hacia el asilo y el refugio internacionales.

Pero lo que sucede, siguiendo con Rancière (ibídem), es que "el excluido no tiene estatuto (...) se convierte en el otro radical", que además amenaza a la comunidad. Dicha amenaza subyace en cierto sentido a los golfistas que aparecen distraídos y absortos en el juego, pero el cual no se podría desarrollar seguramente sin las caras bolsas de golf, los carros, los palos, seguramente fabricados o ensamblados en muchos de los lugares de origen de los migrantes encaramados en la valla. Al analizar la obra de Lyotard (1994) "Los derechos del otro" Ranciére expone que no puede tener derechos un hombre apolítico, históricamente llamado ciudadano. Y a esa llamada de atención también se enfrente la obra de Palazón por cuanto la ayuda humanitaria es inhumana si no cuenta con una regulación que fomente el acceso a la ciudadanía.

Y en cierto sentido, la apelación que Palazón hace al exponer otro tipo de vallas (no las vallas de las concertinas en la frontera de Melilla, sino unas vallas en un recinto privado) tiene también que ver con el desplazamiento que supone hablar de la proliferación de un aparato securitario en aumento a nivel global. Pero aun con el aumento de los muros, los migrantes los saltan. Y es en el contacto donde surge uno de los problemas fundamentales para el Estado: la incertidumbre derivada del ¿quiénes son?, ¿qué vienen a hacer?, ¿cuáles son sus intenciones? Y por tanto hay una exigencia a controlarlos, vigilarlos, eventualmente encarcelarlos (en centros de internamiento para extranjeros, en guettos, en cárceles, en trabajos precarios, en viviendas hacinadas...).

Analizando la obra de Foucault, Mauricio Lazzarato (2006, p. 4) expone un tema que es clave para contextualizar la obra de Palazón: "a través de las estadísticas (otro conocimiento indispensable para los dispositivos de seguridad), se dibuja una cartografía diferencial de la normalidad calculando el riesgo de contagio para cada rango de edad, para cada profesión, para cada ciudad y, dentro de cada ciudad, para cada barrio". Lo que hacen estas estadísticas es precisamente tratar de apuntalar la normalidad para evitar y/o dispersar los riesgos. ¿Pero de qué sirven cuándo los medios hablan de oleadas, marabuntas, hordas? ¿Y de qué sirven cuando no hay posibilidad de censar, ni hay cruce real y objetivo de datos entre países por los que transitan los migrantes internacionales? Como decíamos más arriba, "devenir migrante" es el concepto que utiliza Sandro 
Mezzadra (2005) para exponer las condiciones de inestabilidad, precariedad, incertidumbre y vulnerabilidad a las que todas las personas estamos arrojados por el hecho de vivir en el sistema capitalista. La modernidad eurocéntrica ya no es rígida y estática, sino líquida, según Bauman (2015), lo cual puede ser una buena metáfora para el caso que nos ocupa: "el campo de golf, que costó 5 millones de euros y tiene un mantenimiento anual de 700.000, colinda a lo largo de unos 1.500 metros con la doble valla de seis metros de altura y 12 kilómetros de largo que separa Melilla de Marruecos"1 . Además, siguiendo con Bauman (2016), proliferan los "extraños llamando a la puerta", título de su última obra, publicada en fechas muy próximas a la obra de Palazón. El autor polaco llama la atención ante el peligro de "cansarse de la tragedia de los refugiados" (...) y que las imágenes que aparecen en medios, redes y web muchas veces terminan en el olvido, dejando pasar de largo dichas tragedias (Bauman, 2016, p. 10). Y es frente a ese "no cansarse" donde también se sitúa la foto de la valla aquí expuesta.

Por otra parte, un campo de golf que necesita ingentes cantidades de agua para un lujo elitista mientras que al otro lado nos encontramos con personas que entre otras causas emigran de sus lugares de origen por carecer de acceso al agua potable y a las necesidades básicas. Y aun así son observados como deshechos humanos que vienen a golpear nuestras puertas y a perturbar nuestros tiempos de ocio y disfrute, de ahí el dramatismo de la fotografía. Y es que una definición de arte político, bajo el que obviamente encuadramos la obra de Palazón, es la de "hacer audible en la boca de lo que no se puede hablar" (Bal, 2009, p. 63)

Y lo antedicho nos coloca de nuevo ante las nuevas políticas de la mirada. Estudios poscoloniales y decoloniales visibilizaron las condiciones de asimetría en la construcción de la Modernidad eurocéntrica bajo criterios de subsumir todas las formas de trabajo al capital y bajo criterios raciales. Mientras que feministas chicanas, negras, árabes, indígenas pueden hacer un llamamiento a la diversidad y a las múltiples y heterogéneas formas de ser mujer, autores como Gabilondo exponen acerca de que "la proliferación de palabras sobre el otro no siempre ha coincidido con la escucha al otro" (Gabilondo, cit. en Aznar y López, 2019, p. 51). En este sentido nos interesa la foto del campo de golf pues automáticamente vienen dos imágenes a la cabeza: la respuesta en rotundo NO de Chakravarty Spivak (2003) a si puede hablar el subalterno; y el "mira, un negro" de Fanon (2009) en Piel negra, máscaras blancas".

Un NO que le sirvió a Santiago Sierra (No, global Tour, 2009), en un trabajo de campo performativo multisituado para exponer acerca de la temática que creemos fundamental en Palazón, como es la de las fronteras, en donde la crisis de los refugiados es un claro ejemplo de "resistencia contra el gran mapa del mundo" (Aznar y López Díaz, 2019, p. 190), si bien un mundo cuyo acceso está negado a millones de personas. Pues esa negación también está presente: no a la

1 En “Detrás de una Foto. José Palazón”. Gea Photowords: https://www.geaphotowords.com/blog/detras-deuna-foto-jose-palazon/, consultado el 15/02/2021 
democracia, no a los derechos, no a la ciudadanía, no a un trabajo y no a una vivienda digna...Y por supuesto No a jugar al golf. Democracia fallida, por tanto, aquella que, a menos de la distancia de un tiro de pelota de golf, coloca una valla y se pregunta por qué hay personas dispuestas a arriesgar sus vidas por saltarla. Pero un No, además, que precisamente impide hablar al subalterno precisamente por su calidad de serlo. No tiene lugar de enunciación, dirá Chatravarty Spivak (2003). Y es por ello que es clave el análisis de las fotografías que realiza Benjamin (1989) en La obra de arte en la época de la reproductibilidad técnica, pero que interpreta posteriormente Susan Bück Mors (1993) exponiendo la peligrosidad de la anestesia. Frente a ello, el schock del que hablaba Benjamin y que esta obra de Palazón muestra, pues ya no permite una mirada distraída, sino concentrada. Una mirada que va mucho más allá de estadísticas, de flujos, de "manos de obras" o de "migrantes" para hablar de personas, de vidas, de proyectos migratorios y de condiciones de deshumanización. Y lo hace, además, visibilizando cómo pueden ser obviadas las fronteras.

Y es que con Bhabha (2007), quien analiza la obra de Fanon (2009), Palazón también nos dice "Mira, un negro". Varios negros, muchos negros. Afirma Bhabha (2007, p., 104), citando a Fanon que "eres rico porque eres blanco, eres blanco porque eres rico". Y juegas al golf porque eres blanco y rico, podríamos confirmar (con la excepción de Tiger Woods, quien desde luego si seguimos a Bolívar Echeverría sería un claro ejemplo del proceso de blanqueamiento, y con esto no nos referimos simplemente a procesos de cambios en la pigmentación de piel a lo Michael Jackson). Pues lo que autoriza el discriminar es el eliminar el conocimiento acerca de cómo se construye la diferencia, incluida en este caso una diferencia construida en base a tonalidades de color que se toman como naturalizadas e insertadas en otras categorías discriminatorias más amplias en torno a lo racial, las cuales deben ser constantemente hiperbolizadas, remarcadas y reproducidas en base al estereotipo.

Qué relaciones de poder hay en la obra de Palazón, qué historias geopolíticas o qué narrativas son algunas de las preguntas que subyacen a la fotografía. Entre otras muchas respuestas está la posibilidad de reconocer que el color es un signo de diferenciación tanto político como cultural y que implica procesos (y consecuencias) de inferioridad. Pero estereotipar en base al color es también una de las críticas que la foto del campo-valla trae detrás. Independientemente del proceso que sigue a esta foto (repatriación, devolución en caliente, integración, consecución de ciudadanía, mestizaje cultural, hibridación...) siempre queda en el espectador la pregunta del qué pasó después. Pero sobre todo la pregunta acerca de las condiciones de llegada, el antes. Y es que como dice Bhabha (2007) al hablar del mimetismo, los migrantes encaramados en esta valla serán casi lo mismo, pero no blancos, en una lectura geopolítica desde el colonialismo que históricamente invisibilizó, convirtió, evangelizó, esclavizó, asimiló, proletarizó y persiguió al otro; y que hoy, por ejemplo, trata de que trabaje como mano de obra precaria (¿cargando palos de golf, por ejemplo?). Y esas imágenes de la blanquitud, analizadas entre otros por Bolívar Echeverría (2007) nos sirven para remarcar que la discriminación es un efecto político. Al fin y al cabo, los golfistas que en la foto aparecen van de blanco y dan la espalda a los negros que aparecen al fondo. 
DOI: https://dx.doi.org/10.17561/rtc.20.6156

\section{Linton, 15 libras, tres horas por semana, a 31.50 dólares. Arantxa Araújo}

Y esa discriminación la muestra la segunda de las obras seleccionadas: Linton, 15 libras, tres horas por semana, a 31.50 dólares, de Arantxa Araújo (2017).

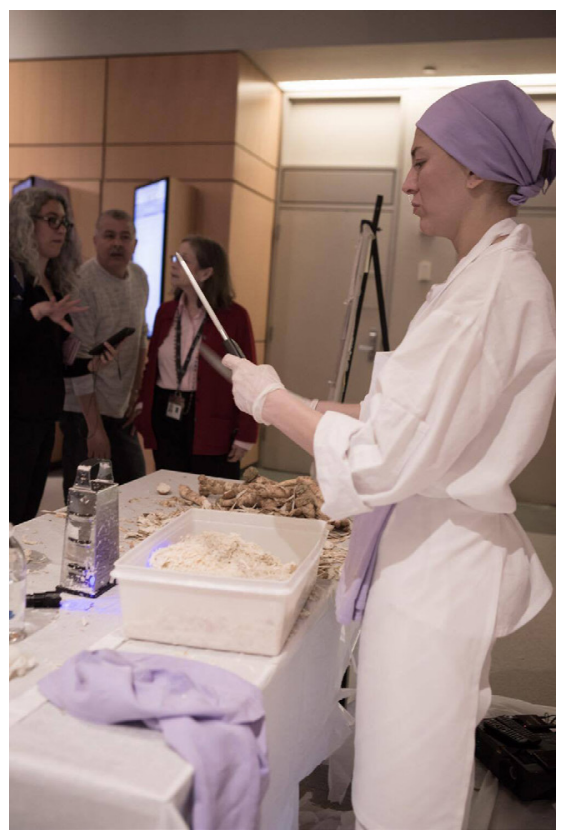

Figura 2.- Linton, 15 libras, tres horas por semana, a 31.50 dólares, Arantxa Araujo (2017) Extraída de: https://vanguardia.com.mx/articulo/una-artista-del-performance-social-arantxa-araujo

La artista mexicana realiza una performance donde pasa varias horas rayando rábanos en una mesa con el fin de visibilizar las condiciones de trabajo de los migrantes mexicanos en la ciudad de Nueva York, lugar donde tuvo lugar la exposición. Allí, en la Universidad, Araújo mostró el proceso por el cual han de pasar los alimentos procesados en restaurantes de lujo con el fin de que clientes de la élite puedan comer sus ostras al gusto. Más allá de mostrar las condiciones laborales precarias interesa esta obra por la ingente labor de análisis de la artista, quien realizó miles de horas de entrevistas y de observación en cocinas de toda la ciudad neoyorkina. Araújo, ya llorando del dolor de picar ajos durante horas y con las manos doloridas, fue interpelada por una persona que visitaban la obra con el fin de que se detuviese. Resultó que dicha persona era la encargada de relaciones públicas de la institución, quien expuso que se debían contar con permisos 
en los restaurantes para manipular alimentos, mientras que Araújo era solo una artista. Le satisfizo a la performance que esta conversación se diese, pues la siguiente vez que alguien entrase en un restaurante sabría de estas condiciones, mal pagadas y en lugares escondidos y recónditos, en el subsuelo del lujo y la ostentación; y por supuesto con salarios precarios. Es de interés esta obra por cuanto conecta no solo con una visión del artista como etnógrafo, sino que además construye un discurso que nos permite elaborar alguna respuesta a la pregunta de Benjamin (1989): ¿Cuál es la posición de una obra con respecto a sus relaciones de producción? Asimismo, sirve para pensar el consumo como distinción (Bourdieu), en un análisis desde el campo culinario y desde el campo artístico, por ejemplo.

Además, si con Manzioni (1960) asistíamos a cómo devorar el arte, título de una de sus famosas obras, aquí incluso podemos observar que la propia comida, su elaboración, es la que devora al público, por cuanto lo interpela. Hemos de recordar en este sentido lo expuesto por Descola, para quien "el aprendizaje de una cultura empieza siempre por los modales en la mesa" (Descola, 2005, p. 46). Pero Araújo va más allá, a las estructuras subyacentes, tanto materiales como ideológicas, que están detrás del acto de consumo. Precisamente su crítica va hacia una nueva modalidad de consumo elitista que en restaurantes de precios onerosos tiene la tendencia de elaborar un ceremonial de la transparencia en el que los comensales pueden ver la elaboración de los productos que van a degustar. Pero para que eso se produzca hay antes toda una cadena global que habla de extracción de materias primas, de intermediarios, de economía informal, de precariedad en los contratos de los trabajadores que van a esos restaurantes, de extracción y de expolio de grandes masas de población para que el producto final pueda ser degustado por una élite, ajena a todas esas cadenas.

Para remarcar todo lo antedicho, y sobre todo poner de relieve las condiciones de vulnerabilidad de los migrantes que trabajan en los subsuelos de los restaurantes, lejos de las miradas de los consumidores, Araújo elabora un ceremonial con el fin de atacar al propio cuerpo (ojos llorosos, manos doloridas, nariz sobresaturada, calor, fatiga...) en la misma lógica que diversos artistas vienen realizando sus obras desde los años 70 (Aznar y López, 2019, p. 79-80). Y sobre todo interesa que estas nuevas obras implican un receptor, por lo cual ya nunca será posible una mirada pura, lo cual recrudece la crítica al "arte por el arte" desde una supuesta neutralidad observadora.

Las condiciones socioeconómicas de los migrantes, pues, son claves para comprender un mundo capitalista cambiante desde los años 60. Los influjos del feminismo, por ejemplo, para exponer la feminización de las migraciones en el contexto de los flujos Norte-Sur puede servir también para colocar en contexto los análisis de los artistas en los que se puede insertar la obra aquí propuesta. A lo que, por supuesto, hemos de agregar el comprender que los procesos de la historia no son algo cerrado, sino con múltiples lecturas, interpretaciones, necesidades de lecturas a contrapelo (como diría Benjamin) y, por supuesto, luces y sombras, así como zonas de relieve 
DOI: https://dx.doi.org/10.17561/rtc.20.6156 Investigación

y vacíos. Y es que Benjamin se hacía eco de lo que sucedía en los boulevares de París a finales del S. XIX y principios del S. XX para recalcar el carácter fantasmagórico de las mercancías. Es en lo estético donde se escondía la explotación de los trabajadores. De la misma manera que lo es en los refinados manteles y en los platos de gourmet en los restaurantes del S. XXI. De la misma manera que Benjamin podía recorrer los escaparates de la ciudad de la luz, hoy en día hay toda una selección de rutas y recorridos por restaurantes dotados de estrella Michelín u otros premios de renombre. Tanto en aquel París como en estos lugares de la posmodernidad lo que se esconde es la vida puesta a disposición del capital por parte de los trabajadores; en el caso que nos ocupa, mano de obra migrante que no sale a saludar a los comensales. Se trata de vidas vaciadas de contenido para que otros puedan llenar las suyas.

\section{4. "Escultura por un mundo en tránsito. Los viajeros". Bruno Catalano}

Y es con vacíos con los que juega la tercera de las obras seleccionadas, también de temática migrante: Escultura por un mundo en tránsito. Los viajeros, de Bruno Catalano (2014).

Situadas por la ciudad de Marsella en 2013, colocan al observador en la tesitura de preguntarse si es con la llegada a la nueva ciudad donde se podría completar la figura (la integración, la ciudadanía, el ser persona plena) o si es precisamente debido a la práctica de viaje desde donde analizar la pérdida, la ausencia, la incompletud del ser. En este sentido, la vida del migrante, en esta escultura a tamaño real, es también un espejo lacaniano desde el que poder representar los trozos de la identidad. Además, esta obra sirve para comprender el velo de la mirada, pues "cuando las vemos, nos miran", si es que las podemos leer, compartimos con Didi-Huberman (2017). Se siente, pues, una pérdida.

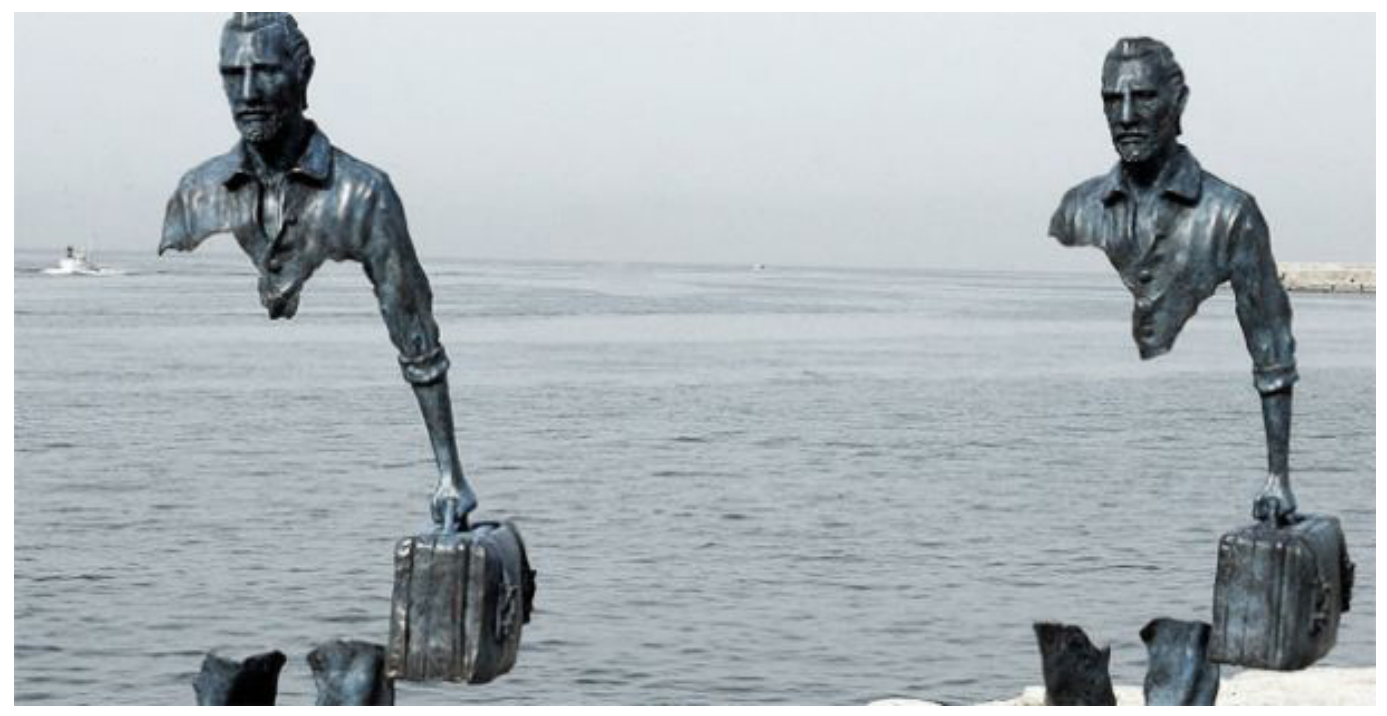

Figura 3.- Escultura por un mundo en tránsito. Los viajeros, de Bruno Catalano (2014) Extraída de: https://vavel.media/es/2015/09/11/arte/539053-los-viajeros-de-bruno-catalano.html 
Pero en primer lugar podríamos empezar por el subtítulo de la obra, lo cual ya nos coloca sobre aviso. Se trata de viajeros. No de refugiados, ni de migrantes, ni de extranjeros, ni de asilados, ni de turistas. Y es que ya decía Marc Augé (1998) que viajar hay que viajar, pero no hacer turismo, pues no es lo mismo, la experiencia es diferente. De la misma manera que sucede con las otras prácticas de viaje antedichas. Es interesante recalcar que con toda salida de hogar se produce una pérdida que muy bien ha sabido analizar Sayad (2010) en cuanto se da una doble ausencia, al salir y al llegar a un nuevo lugar, y que de nuevo nos retrotrae a Bhabha, que en su análisis de las identidades expone cómo el extranjero es un ente entre dos mundos, un in-between, ni de aquí, ni de allá. Y eso parece precisamente significar Catalano, enfatizando esta idea al colocar sus estatuas por la ciudad de Marsella, puerto importante de Europa y lugar de tránsito de diversos pueblos a lo largo de la historia. Y es que el tema fundamental, ese tránsito del que habla el título de la obra, es algo inherente a la identidad del viajero que llega a un nuevo hogar y trata de acomodarse, integrarse. Siempre deja algo atrás y de ahí que el autor borre parte del cuerpo de su obra, espacio vacío que es atravesado por la mirada del espectador, el cual dependiendo de donde se sitúe podrá, de alguna manera, terminar la escultura con el azul del mar o con el paisaje urbano de la ciudad. Pues al fin y al cabo, es la mirada la que condiciona la experiencia, a la vez que es condicionada por ella. Y en esa relación dialéctica nos interesa comprender que la identidad no es una esencia ni algo creado ex ante sino que es en su constante construcción como se fraguan las relaciones y las subjetividades. Para ello, la antropología nos ha mostrado que ante la incertidumbre toda sociedad dota de sentido su relación con lo proveniente del exterior, y así por ejemplo deben pasar por ritualizar al "otro": exorcizándolo, aislándolo, excluyéndolo, adorándolo, encerrándolo... o pidiéndole papeles de ciudadanía, de trabajo, de residencia, de convivencia familiar, etc. Y es lo que nos lleva a pensar que la obra de Palazón, al colocar en el centro ese hueco que deja en el cuerpo, precisamente nos habla de ese concepto constructivista de la vida migrante que nunca termina de completarse, entre otras cosas porque nuestra mirada hacia él tampoco lo hace. Para el ciudadano asentado (o supuestamente asentado) en una sociedad, el otro entraña un riesgo.

La rabia, la esperanza y el miedo forman parte de la mayoría de las situaciones de riesgo. Nadie toma una decisión con la que arriesgue algo sin antes haber consultado a sus vecinos, a sus familiares o a sus amigos del trabajo. Éstos constituyen el grupo de apoyo que proporcionará ayuda si las cosas se tuercen (Douglas, 1991, p. Xx)

Y es precisamente en la intención de que no se tuerzan las cosas donde radica la necesidad de visibilizar al otro como un riesgo en potencia o, en el caso que nos ocupa, como alguien por concluir.

Pero es que además Palazón elabora todo un juego imaginativo por cuanto reta al espectador de la obra a imaginarse cómo sería el final de la misma. Y en ese proceso de reflexión surge la pregunta clave: ¿se está terminando de formar ese cuerpo, si siguiéramos con la linealidad 
DOI: https://dx.doi.org/10.17561/rtc.20.6156 Investigación

del proyecto migratorio?, o al contrario ¿terminaría por corromperse del todo, hasta llegar a la plena invisibilidad? Y es que son estas las jerarquías en torno a la movilidad que pueblan el planeta: las asimetrías entre aquellas personas que pueden viajar, aquellas otras que sueñan con viajar, y la última categoría: la de quienes ni tan siquiera están en la opción de poder imaginarse el viajar. Categorías expuestas por ejemplo por Appadurai (2001), para quien vivimos insertos en una serie de paisajes (étnicos, económicos, tecnológicos, ideológicos) en donde la entrada y salida de los mismos pasa por la imaginación (en un sentido teórico-práctico) a la hora de desarrollar resistencias frente al sistema.

\section{Conclusiones}

Roman Ondak (2012) elaboró una propuesta minimal en 2012 donde llevaba a cabo una instalación cuyo centro era el ala de un avión en la que, como los que han viajado sabrán, si les ha tocado asiento de ventana al lado de un ala se puede leer el cartel: "no caminar fuera de esta área".

A Ondak le interesa la relación entre prohibición y arte, de la misma manera que es central para lo expuesto más arriba en torno a la securitización (no pasar la valla), la visibilización (no conocer las condiciones) o la exclusión (no permitir que el cuerpo termine de hacerse). Y es que ¿quién querría caminar fuera de esa área? Desde luego los cómodos viajeros de clase ejecutiva ni tan siquiera ven el cartel y los que viajan en clase económica estarían lejos de querer posarse sobre esa zona, lo cual sería muy mala señal (sobre todo si es que se da tal situación durante el vuelo).
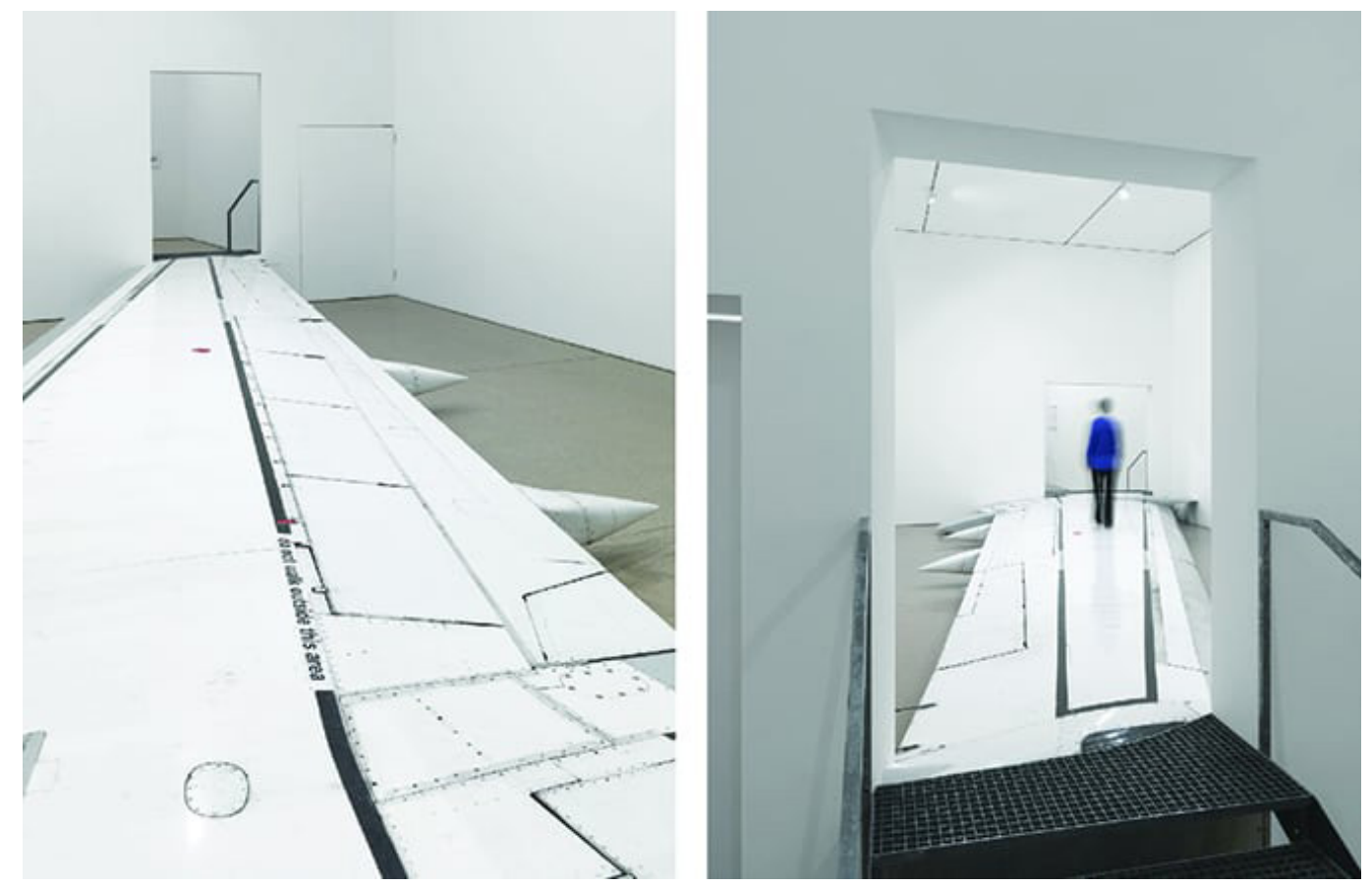

Figura 4.- Do not walk outside this área (2012) Extraída de: https://adrastuscollection.org/roman-ondak-performing-heights/?lang=es 
A Ondak le interesa la relación entre prohibición y arte, de la misma manera que es central para lo expuesto más arriba en torno a la securitización (no pasar la valla), la visibilización (no conocer las condiciones) o la exclusión (no permitir que el cuerpo termine de hacerse). Y es que ¿quién querría caminar fuera de esa área? Desde luego los cómodos viajeros de clase ejecutiva ni tan siquiera ven el cartel y los que viajan en clase económica estarían lejos de querer posarse sobre esa zona, lo cual sería muy mala señal (sobre todo si es que se da tal situación durante el vuelo).

Es así que Ondak deja lugar a la imaginación, en conexión con el análisis de nuestras obras precedentes, pero también con la imaginación sugerente, según Appadurai, desde el foco de la mirada. La persona que ve el cartel debe hacer toda una proyección para imaginarse a quién se le ocurriría tener que recurrir a la lectura de tal prohibición para pensar que no debería estar ahí: los viajeros, obviamente no; los pilotos, tampoco; y los operarios de seguridad del avión, ya deberían saberlo. Estamos, pues, ante un cartel que, por hiperbólico, quizá sobre. Pero que aun así no puede no ser colocado, precisamente para hacer de la seguridad un gran imaginario. Y, además, un imaginario en torno a ese NO del que también nos hablaba Santiago Sierra.

Pero si algo ha mostrado el arte es que frente a las gramáticas jurídicas, administrativas $\mathrm{y}$ territoriales que precisamente privilegian el dualismo (a un lado u otro de la valla, cuerpo terminado o no, comensal del restaurante o trabajador migrante precario), lo que hacen es colocar todo un campo de zonas grises, de intersticios, de zonas porosas. Y esto es clave también para comprender el mundo en tránsito, líquido (con Bauman) en que vivimos. Ya Benjamin exponía cómo el schock (de la imagen, de la cinta de cine, de la escena) es positivo para despertarnos de una mirada anestesiada y distante.

Si desde las Ciencias Sociales muchos autores vienen explicando el campo migratorio como una serie de nodos en conexión, donde los dualismos ya no sirven para acotar la realidad (de hecho, las teorías push-pull han sido criticadas y completadas desde hace décadas), la conexión de esto con las propuestas artísticas sirve para descentrar nuestra mirada, cambiar la lente, proponer nuevos horizontes y proponer nuevos paisajes. Unos paisajes en donde el otro somos también nosotros. Y todo ello bajo una imaginación de la otredad no como conflictiva sino como necesaria, complementaria y convivencial.

\section{Referencias}

Appadurai, Arjun (2001). La modernidad desbordada. Buenos Aires: Fondo de Cultura Económica.

Arendt, Hannah (2020). La condición humana. Barcelona: Paidós.

Augé, Marc (1998). Viaje imposible. Barcelona: Gedisa.

Aznar, Yayo y López Díaz, Jesús (2019). Arte desde los setenta: prácticas en lo político. Madrid: Uned. Editorial Universitaria Ramón Areces. 


\section{Tercio Creciente}

DOI: https://dx.doi.org/10.17561/rtc.20.6156 Investigación

Bal, Mieke (2009). Arte para lo político. Estudios visuales: Ensayo, teoría y crítica de la cultura visual y el arte contemporáneo, (7), 40-65.

Barth, Frederic (1976). Los grupos étnicos y sus fronteras. México: Fondo de cultura económica.

Bauman, Zygmunt (2015). Modernidad líquida. México: Fondo de cultura económica.

Benjamin, Walter (1989). La obra de arte en la época de su reproductibilidad técnica. Discursos interrumpidos I, p. 15-57.

Bhabha, Homi (2007). El lugar de la cultura. Buenos Aires: Ediciones Manantial.

Bourdieu, Pierre (2016). La distinción: criterio y bases sociales del gusto. Madrid: Taurus.

Buck-Morss, Susan (1993). Estética y anestésica. Una revisión del ensayo de Walter Benjamin sobre la obra de arte. La balsa de la Medusa No 25, p. 55-98.

Chakravorty Spivak, Gayatri. (2003) ¿Puede hablar el subalterno? Revista colombiana de antropología, 39, 297-364. https://doi.org/10.22380/2539472X.1244

Davis, Mike (2020). Control urbano. Más allá de Blade Runner. Barcelona: Virus Editorial.

Davis, Mike, (2006). Planeta de Ciudades Miseria. Madrid: Foca.

Descola, Phillippe (2005). Las lanzas del crepúsculo. Relatos jíbaros. Alta Amazonía. Buenos Aires: Fondo de Cultura Económica.

Didi-Huberman, George (2017). Lo que vemos, lo que nos mira. Buenos Aires: Manantial.

Douglas, Mary (1996) Pureza y Peligro. Un análisis de los conceptos de contaminación y tabú. Madrid: Siglo XXI.

Echeverría, Bolivar (2007). Imágenes de la blanquitud. Sociedades icónicas. Historia, ideología y cultura en la imagen, $n^{\circ} 21,15-32$.

Fanon, Fratnz (2009). Piel negra, máscaras blancas. Ediciones Akal.https://doi. org/10.7476/9788523212148

Ferrocarril Clandestino, Médicos del Mundo Madrid y SOS Racismo Madrid (2010) Voces desde y contra los Centros de Internamiento para Extranjeros. Falta ciudad: Ferrocarril Clandestino, Médicos del Mundo Madrid y SOS Racismo Madrid

Foster, Hal (2001). El artista como etnógrafo. El retorno de lo real. La vanguardia a finales de siglo.

Foucault, Michel (1982). Las palabras y las cosas: una arqueología de las ciencias humanas. Madrid: Siglo XXI. 


\section{Tercio Creciente}

DOI: https://dx.doi.org/10.17561/rtc.20.6156 Investigación
Maneras de habitar los espacios desde la mirada estética Julio 2021

Foucault, Michel (1967). Historia de la locura en la época clásica. México: Fondo de Cultura Económica.

Garnier, Jean Pierre (2015). La invisibilización urbana de las clases populares. Papeles de Relaciones Ecosociales y Cambio Social, 130, 29-45.

Goffman, Erving (2001). Internados. Buenos Aires: Amorrortu.

Harvey, David (2008). El derecho a la ciudad. New Left Review, 53(4), 23-39.

Helmut, Dietrich (2008). El Mediterráneo como nuevo espacio de disuasión. En AAVV (2008) Frontera Sur. Nuevas políticas de gestión y externalización del control de la inmigración en Europa. Madrid: Virus Editorial.

Lazzaratto, Maurizio (2006). Biopolitique/Bioéconomie. Multitudes, n²2. https://doi.org/10.3917/ mult.022.0051

Levinas, Enmanuel (2000). La huella del otro. México: Taurus.

Lyotard, Jean-François (1994). Los derechos del Otro. Conferencia presentada en la Universidad Nacional de Colombia en 1994, Bogotá, Colombia.

Pratt, Mary Luoise (2010). Ojos imperiales: literatura de viajes y transculturación. México: Fondo de cultura económica.

Rancière, Jacques y Tijoux, Maria Emilia (2005). El viraje ético de la estética y la política. Santiago de Chile: Eds. Palinodia.

Sassen, Sakia (2015). Expulsiones. Brutalidad y complejidad en la economía global. Madrid: Katz. https://doi.org/10.2307/j.ctvm7bdqr

Schutz, Alfred (1964). El forastero. Ensayo de Psicología Social. Teoría social. Buenos Aires: Amorrortu.

Trouillot, Michael Rolph (2017). Silenciando el pasado: El poder y la producción de la Historia. Comares. 